\title{
Physical growth and nutritional status of Mexican infants from newborn to two years of age
}

Samuel Flores-Huerta, MD,(I) Miguel Klünder-Klünder, MSc, ${ }^{(!)}$Onofre Muñoz-Hernández, MD, MSc.(I)

Flores-Huerta S, Klünder-Klünder M, Muñoz-Hernández O. Physical growth and nutritional status of Mexican infants from newborn to two years of age. Salud Publica Mex 2012;54 suppl I:S82-S89.

\begin{abstract}
Objective. To determine the nutritional status of Mexican infants under two years of age. Materials and methods. Five nutritional surveys, three being representative of the nation, were assessed using several anthropometric indicators, with reference to the WHO 2006 growth standard. Results. From national surveys, the incidence of low birth weight ranged from 8.9 to $8.1 \%$ and was higher in rural areas. At two years of age, the prevalences of stunted growth, wasting and being overweight ranged from 25.6 to $16.1 \%, 4.5$ to $1.9 \%$ and 6.3 to $10.8 \%$, respectively, between 1988 and 2006 . The combination of being overweight with stunted growth increased with age, particularly in rural areas. Figures presented in non-national surveys compared with national surveys demonstrate a lower incidence of low birth weight, similar levels of stunted growth, being overweight and obesity, and a little higher for wasting. Conclusion. Policies are required to be implemented to prevent nutritional diseases associated with stunted growth, being overweight and obesity.
\end{abstract}

Key words: low birth weight; nutritional status; overweight and obesity; Mexico
Flores-Huerta S, Klünder-Klünder M, Muñoz-Hernández 0 . Crecimiento físico y estado de nutrición de los niños mexicanos, del nacimiento a los dos años de edad. Salud Publica Mex 2012;54 supl I:S82-S89.

\section{Resumen}

Objetivo. Conocer el estado nutricio de niños mexicanos menores de dos años. Material y métodos. De cinco encuestas, tres de ellas nacionales, se evaluaron varios indicadores antropométricos, usando como referente el estándar de crecimiento de OMS, 2006. Resultados. En las encuestas nacionales la incidencia de peso bajo al nacer va de 8.9 a $8.1 \%$, siendo mayor en las áreas rurales. A los dos años de edad la prevalencia de desmedro va de 25.6 a $16.1 \%$; de emaciación de 4.5 a $1.9 \%$ y la de sobrepeso y obesidad va de 6.3 a $10.8 \%$, en 1988 y 2006 respectivamente. El sobrepeso concurrente con desmedro aumenta conforme aumenta la edad, especialmente en áreas rurales. Las cifras en las encuestas no nacionales, comparadas con las nacionales, muestran menor incidencia de peso bajo al nacer, valores similares para desmedro y sobrepeso y ligeramente mayores para emaciación. Conclusión. Se requieren políticas de salud para prevenir enfermedades de rezago como desmedro y otras emergentes como el sobrepeso.

Palabras clave: peso bajo al nacer; estado de nutrición; sobrepeso y obesidad; México

(I) Hospital Infantil de México Federico Gómez. México DF, México.

Received on: February 10, 2011 - Accepted on: September 8, 2011

Corresponding author: MD. Samuel Flores-Huerta, Hospittal Infantil de México Federico Gómez. Dr. Márquez I62, Col. Doctores. 06720, Delegación Cuauhtémoc. México DF, México.

E-mail: floreshuertamd@gmail.com 
$\mathrm{P}_{\mathrm{v}}$ revious nutritional status and health affect an individual's present health status, and influence their future health. ${ }^{1,2}$ In this context, birth weight is indicative of the quality of healthcare that the newborn received in utero and in turn, it is the first indicator for evaluating their subsequent growth. In situations of undernourishment or an increased requirement for energy to fight infection, the body develops adaptive mechanisms to survive including the delay of weight gain and growth. This does not produce clinical manifestations of disease, but reduced physical growth predisposes children to suffer from a greater number of infectious diseases than children with normal growth characteristics. This in turn leads to higher rates of mortality. In individuals that survive such diseases, retarded growth can affect intellectual and emotional development, altering their human development. ${ }^{3}$

On the contrary, individuals who have lived in obesogenic environments since early life suffer various metabolic disorders including type 2 diabetes mellitus (T2D) and cardiovascular diseases, which are leading causes of death among adults worldwide.*

Information concerning the nutritional status of infants less than two years of age is scarce in Mexico; the first studies date from the 1990s; predominantly, children younger than five years of age have been studied, and children under the age of two are not significantly represented. In an approach to investigating the nutritional issues affecting children, this paper describes the prevalence of several nutritional indicators using information from various surveys. However, associations between these nutritional indicators and determinant variables such as energy intake and nutrients are not analyzed; energy consumption and its association with infectious morbidity are not analyzed.

Understanding the role of these nutritional indicators from birth until two years of age is crucial, as this is when cerebral growth is completed, concluding the first major stage of a child's growth and development.

\section{Materials and methods}

Nutritional surveys conducted in Mexico with a national scope that used probabilistic sampling, which is suitable for extrapolating the findings and applying them to larger populations, were analyzed. Furthermore, these

\footnotetext{
* Consejo Nacional de Población. Principales causas de mortalidad en México 1980 - 2007. Documento de Trabajo para el XLIII Periodo de Sesiones de la Comisión de Población y Desarrollo "Salud, morbilidad, mortalidad y desarrollo". Nueva York, 2010.
}

studies included children less than two years of age and recorded accurate measurements of their weight and height. The surveys that fulfilled with these criteria were three National Nutritional Surveys conducted in 1988 (ENN 88), 1999 (ENN 99) ${ }^{5}$ and 2006 (ENSANUT 2006). ${ }^{6}$ Two other surveys were also considered; the survey concerning dietary practices, nutritional status and healthcare in children under two years of age in Mexico, 2004 (IMSS 04), ${ }^{7}$ which included only children who attended the Mexican Institute for Social Security (Instituto Mexicano del Seguro Social, IMSS), and a survey for the Medical Insurance for a New Generation (Seguro Médico para una Nueva Generación, SMNG 09) ${ }^{8}$ conducted in 2009. It is important to note that the latter two surveys were conducted nationwide and were representative of their respective populations. All surveys were approved by Ethical Committees and Research Boards of their respective institutions.

The incidence of low birth weight (LBW) $(<2500 \mathrm{~g})$ was calculated for urban and rural areas from the ENN 99, ENSANUT 2006, IMSS 04 and SMNG 09 surveys. Information concerning gestational age was absent from the national nutrition surveys, therefore the proportion of LBW between term versus preterm newborns was not estimated. With the exception of the IMSS 04 survey, in which the birth weight was measured minutes after birth, the birth weight was reported by the mother and verified if possible using vaccination cards and birth certificates.

In each of the surveys, the infant's weight and length were measured by trained personnel following international anthropometric guidelines and using appropriate instruments. ${ }^{4-10}$ Diagnosing the nutritional status of children was carried out using the same index and cutoff point in each survey, and using the WHO growth standard 2006 as a reference. ${ }^{11,12}$ Stunting was considered present if the length-for-age (L/A) ratio was $<-2 \mathrm{Z}$ scores. Wasting was present if the weight to length ratio (W/L) was $<-2 \mathrm{Z}$ scores, and being overweight including obesity was considered present if the body mass index (BMI) was $>2 \mathrm{Z}$ scores. Values were considered valid if $\mathrm{Z}$ scores were between -5.5 and +3 for $\mathrm{L} / \mathrm{A},-4.2$ and +5 for $\mathrm{W} / \mathrm{L}$ and -4.2 and +5 for BMI, according to ENSANUT 2006. Children who presented with none of the above afflictions were considered to have a normal nutritional status. When necessary, databases from the National Health Nutrition Surveys were subjected to supplementary analysis, requesting authorization from the National Institute of Public Health.

Data were analyzed using STATASE 11.0 software. To obtain the prevalence of malnutrition according to the WHO 2006 standard, macro procedures provided by WHO 2006 on their website ${ }^{11}$ for STATA were used. Ratios and measurements concerning central and dis- 


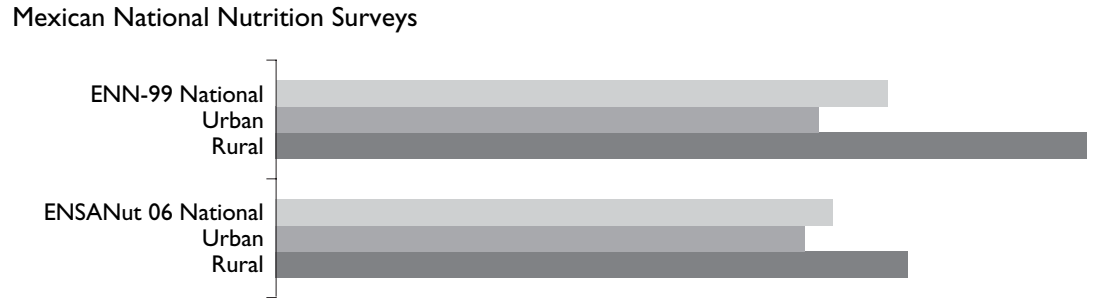

IMSS and SMNG National Surveys

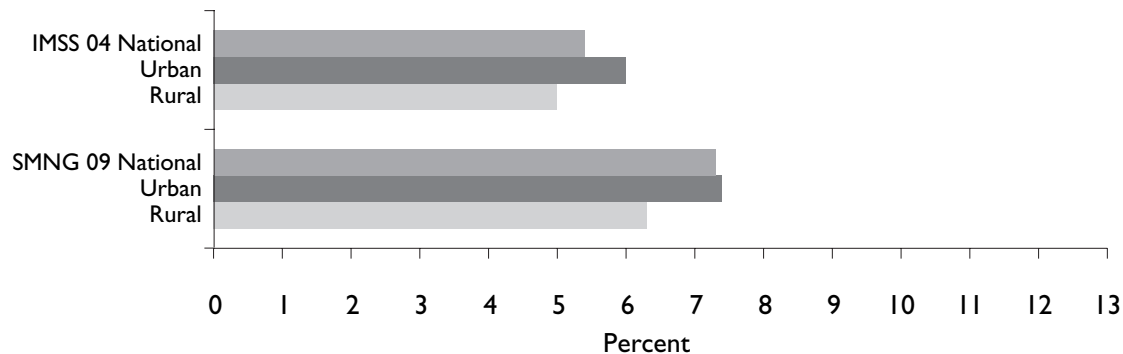

Figure I. Incidence of low birth weight in several National Nutrition Surveys (ENN 99, imSS 04, enSANut 06 AND SMNG 09) ACCORDING TO RESIDENCE AREA (URBAN OR RURAL) AND GESTATIONAL AGE

persion trends were calculated when necessary, with the expansion factors corresponding to the relevant sample or sub sample.

\section{Results}

Low birth weight. The incidence of LBW is presented in figure 1 in terms of residence area and gestational age. The upper panels present data from the national surveys and the lower panels present data from the non-national surveys. In the ENN 99, the total incidence of LBW was $8.9 \%$, decreasing to $8.1 \%$ in ENSANut 2006; both surveys demonstrate a higher incidence in rural than urban areas, although it had decreased by 2006. In the non-national surveys, the LBW incidence is lower than in national surveys; the total incidence in IMSS 04 was $5.4 \%$ and in SMNG 09 was $7.3 \%$, demonstrating that urban areas have a higher incidence than rural areas. Low length for age. The trend and prevalence for stunting are presented in Figures 2 and 3. Figure 2 compares the Z score for length of infants from the ENSANUT 2006 survey with the non-national surveys; the continuous lines represent data for urban populations, while the broken lines are for rural populations. At birth is interesting to note that the length of infants from IMSS 04, from urban and rural areas, is above the average of the reference. However, deterioration of length in these infants is evident after birth. For rural populations, the $\mathrm{Z}$ score of length for age decreases rapidly, crossing the average line when infants are 1 month old; urban infants cross this line at 6 months of age. The length deterioration continues, being more remarkable in rural than in urban infants. No information was available concerning the first semester of life in SMNG children. In summary, stunting in urban children at 2 years of age is between 0 and $-1 \mathrm{Z}$ score, whereas stunting in rural children is between -2 and $-1 \mathrm{Z}$ score. Figure $3 \mathrm{~A}$ demonstrates the prevalence of stunting in the first and second semesters of the first year, and in the second year of life. In the figure, the first three columns concern the Mexican National Surveys ENN 88, ENN 99 and ENSANUT 2006, respectively; the next two columns concern non-national surveys. In the first semester there is no obvious trend present, but in the following two stages the prevalence of stunting increases compared with the previous stage. During the second semester of the first year of life, the prevalence of stunting in ENN 88 was 17.5\%, decreasing to $12.8 \%$ in ENSANUT 2006. Figures from non-national surveys are a little lower than values reported by ENSANUT 2006. During the second year of life, there is a rise in the prevalence of stunting, but there was a notable reduction in this problem during the years between the studies; in ENN 88 the prevalence was $25.6 \%$, but in ENSANUT 2006 it was $16.1 \%$. The figures in the other surveys, IMSS 04 and SMNG 09, were comparable to ENSANUT 2006. It is important to note that stunting in each of the 


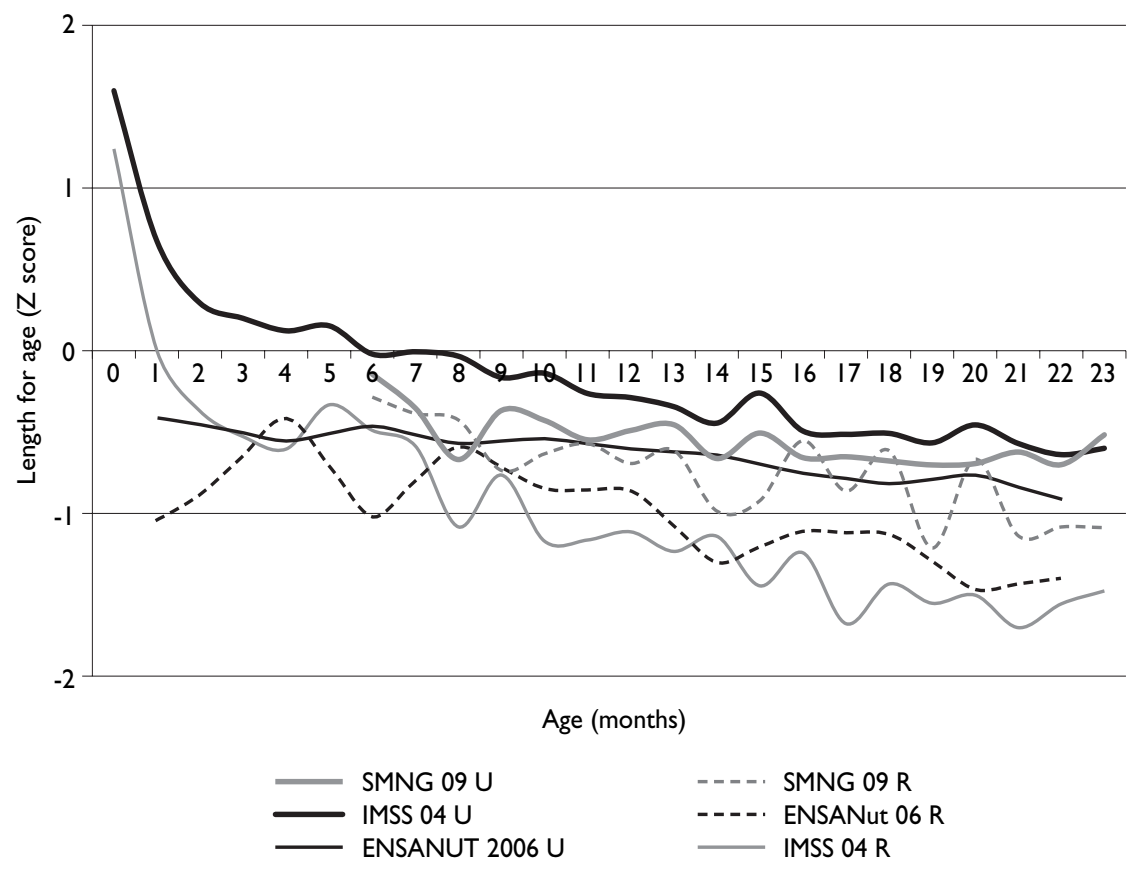

FIGURE 2. Z SCORES OF LENGTH FOR AGE IN CHILDREN UNDER TWO YEARS FROM VARIOUS SURVEYS, IN TERMS OF URBAN OR RURAL AREAS OF RESIDENCE, USING AS A REFERENT THE WHO 2006 GROWTH STANDARD

surveys was calculated using the same indicator, cutoff point and reference.

Wasting. This problem is referred to as an imbalance in which the weight is below normal according to the height reached by the individual. Data concerning this are presented in Figure 3B, and compare the national and non-national surveys. In the first semester, prevalence decreases from 11.8 to 4.4 and 4.7\% in ENN 88, ENN 99 and ENSANUT 2006, respectively; however, for the same stage, IMSS 04 demonstrates a prevalence of $7.3 \%$. In the second semester, figures vary from 6.1, 1.9 and $4.5 \%$ for national surveys, whereas in the non-national surveys the figures are comparable with ENSANUT 2006. In the second year of life, the prevalence for national surveys decreases from 4.5 to 2.8 and $1.9 \%$. However, the non-national surveys demonstrate a higher prevalence of approximately 3 percent.

Overweight including obesity. Figure $3 \mathrm{C}$ presents the prevalence of overweight including obesity in children under the age of 2 . In the first semester, the national surveys demonstrate a prevalence of $4 \%$ (ENN 88), 5.6\% (ENN 99) and 5.7\% (ENSANUT 2006). For the same period, the IMSS 04 survey demonstrates a prevalence of 7.4 percent. In the second semester of life, the figures are 5.5\% (ENN 88), 6.6\% (ENN 99) and 6.4\% (ENSANUT 2006), each of these values being higher than the previ- ous life stage. The value for IMSS 04 is $8.3 \%$, the highest figure. In the second year of life, the prevalence is $6.3 \%$ (ENN 88), 10.0\% (ENN 99) and 10.8\% (ENSANUT 2006), all values being higher than the former periods for each of the surveys. The IMSS prevalence was comparable with ENSANUT 2006.

Prevalence of stunting concurrent with overweight including obesity. Table I depicts the prevalence of this condition in rural and urban areas during the first two years of life. No information was available for this indicator in the ENN 88 study. However, in the national nutrition surveys, an increase in this condition was evident, and the problem was higher in rural than urban areas. In children between 18 and 23 months of age, ENSANUT 2006 presents higher figures for this condition than ENN 99; for urban children the figures were $4.2 \mathrm{vs} .1 .3 \%$, and for rural areas the values were 3.6 vs. $2.1 \%$. In the non-national surveys, the figures presented in IMSS 04 for urban children are similar to urban children in ENSANUT 2006. However, rural children in this survey have the highest prevalence in each semester, reaching $11.8 \%$ in the fourth semester.

\section{Discussion}

With regard to growth, environmental factors, predominantly in terms of available nutrition and life style, 
A

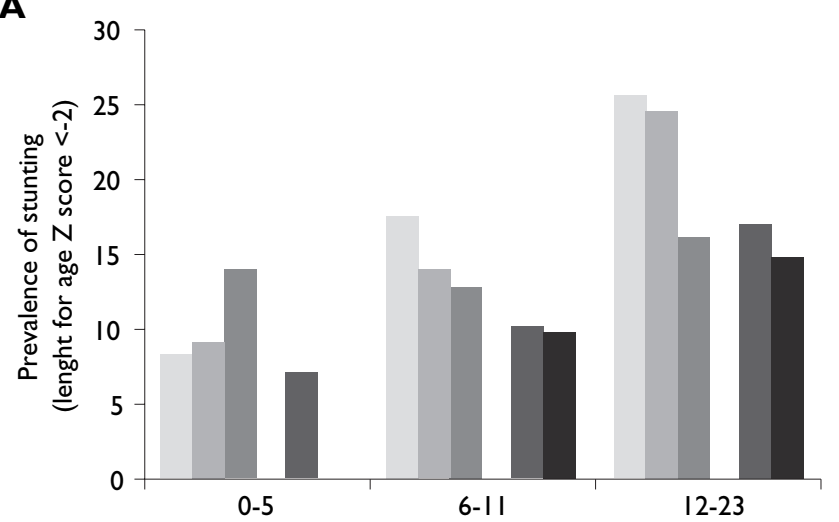

Age (months)

B

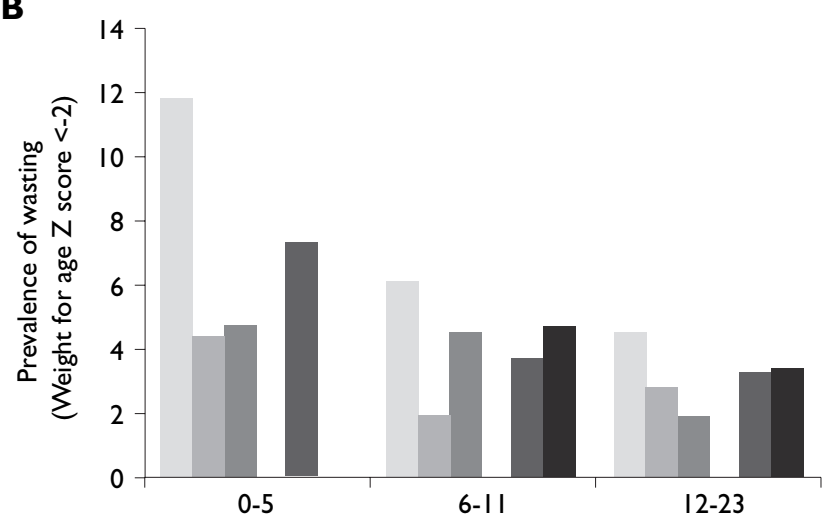

Age (months)

C

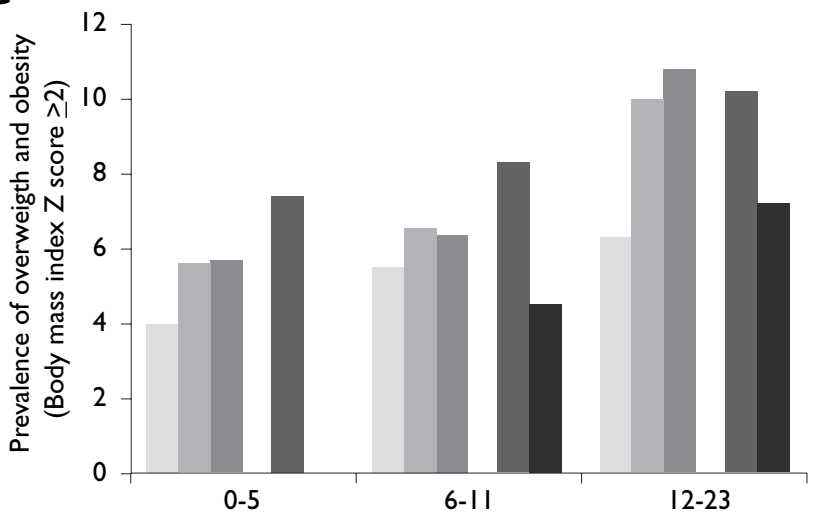

Age (months)
Mexican National Nutrition Surveys ENN 88

ENN 99

ENSANUT 2006

IMSS and SMNG National Surveys

IMSS 04

SMNG 09
Mexican National Nutrition Surveys ENN 88

ENN 99

ENSANUT 2006

IMSS and SMNG National Surveys IMSS 04

SMNG 09
Mexican National Nutrition Surveys ENN 88

ENN 99

ENSANUT 2006

IMSS and SMNG National Surveys IMSS 04

SMNG 09

Figure 3. Prevalence of stunting (A), Wasting (B) and overweight and obesity (C) in Children under two years of age, according to various National Nutrition Surveys, using as referent the WHO 2006 growth standard 
TABLE I

Prevalence of stunting concurrent With being overWeight and obesity in ChildRen UNDeR tWo years of age, BY AREA OF RESIDENCE, URBAN OR RURAL

\begin{tabular}{|c|c|c|c|c|c|c|c|c|}
\hline \multirow{3}{*}{$\begin{array}{l}\text { Age } \\
\text { (months) }\end{array}$} & \multicolumn{4}{|c|}{ México's National Nutrition Surveys } & \multicolumn{4}{|c|}{ IMSS 04 SMNG 09} \\
\hline & \multicolumn{2}{|c|}{ ENN 99} & \multicolumn{2}{|c|}{ ENSANUT 2006} & \multicolumn{2}{|c|}{ IMSS 04} & \multicolumn{2}{|c|}{ SMNG 09} \\
\hline & Urban & Rural & Urban & Rural & Urban & Rural & Urban & Rural \\
\hline $0-5$ & 0.4 & 0.0 & 1.2 & 1.0 & 1.2 & 3.9 & - & - \\
\hline $06-11$ & 0.2 & 0.2 & 1.8 & 1.0 & 2.0 & 8.5 & 1.1 & 0.2 \\
\hline $12-17$ & 0.8 & 1.5 & 1.9 & 3.4 & 3.4 & 12.6 & 2.1 & 1.4 \\
\hline $18-23$ & 1.3 & 2.1 & 4.2 & 3.6 & 3.8 & 11.8 & 2.5 & 1.8 \\
\hline
\end{tabular}

All values are percentages, unless otherwise indicated

clearly modify its expression. To maintain standardized surveillance on physical growth it was relevant to use the growth standard, which WHOlaunched in 2006; the results will be discussed in terms of this standard.

Low birth weight. The incidence of LBW was higher in the National surveys, predominantly in rural areas; between the two surveys the incidence has decreased 0.8 PP. The highest values are explained by these surveys representing the whole population rather than subsamples as is the case in the IMSS 04 and SMNG 09 surveys. However, the lowest incidence of LBW was observed in the IMSS 04 survey, which could be an outcome of health surveillance of the pregnant mother and better socioeconomic conditions of the households protected by IMSS. The highest incidence occurs in urban areas as hospitals with facilities for solving such problems are located in these areas, receiving referrals of patients experiencing pregnancy-related problems. ${ }^{13}$ Concerning its relevance, LBW has been associated with non-communicable diseases affecting adults including T2D and hypertension, enough rationale to signify that these conditions require high priority care. Other countries with higher poverty levels have LBW indices of $16 \%$ or higher. ${ }^{14}$

Stunting. Stunted growth deserves close attention in terms of infant healthcare as it appears early in life. This alteration has at least two dimensions: the first is that the length of a child moves further away from the WHO Standard as age increases, as this phenomenon is cumulative. The prevalence of stunting increases and by the second year of life stunting affects $~ 15 \%$ of infants. UNICEF reports a prevalence of $15.5 \%$ for countries in Latin America and the Caribbean. ${ }^{14,15}$ Increased weight is likely to be due to inappropriate feeding practices of young children; during the second semester and second year, there is a requirement to increase the consumption of food from animal sources. ${ }^{8}$ However, in the second dimension of analysis, the prevalence of this problem has fallen 9.1 PP between ENN 88 and ENSANUT 2006, raising questions concerning whether the results indicate specific interventions or improving healthcare. In terms of specific interventions, children covered by the Oportunidades program receive nutritional supplements that delivery energy, protein and micronutrients. However, benefits for linear growth are inconclusive and even contradictory. While some studies demonstrate benefits for linear growth in the poorest children younger than six months ${ }^{16,17}$ other communitarian assays did not demonstrate an effect on growth when poor children received this supplement. ${ }^{18}$ This indicates that stunting is an issue that could be linked to other factors such as improving the quality of medical care.${ }^{19}$ Addressing the issue of stature is not only important for achieving success in many occupational, recreational and sporting activities, but also for reducing low stature and obesogenic lifestyles, which contribute to overweight including obesity in stunted children, and for their overall development.

Wasting. Children who are underweight for their height are an approximation to cases of acute malnutrition, which in more severe cases require hospital care, regardless of whether their stature is normal or stunted. In the community, such cases are part of the vicious cycle of infection-malnutrition-infection, which results in deteriorated nutritional status. ${ }^{20}$ In the second year of life, the highest prevalence is $4.5 \%$, corresponding to National Nutrition Survey 1988 figures, and the lowest incidence is $1.9 \%$, as reported in ENSANUT 2006. This signifies that the problem had been reduced thanks to several public health measures undertaken in the last decade..$^{19}$ The prevalence of this form of malnutrition is similar to that reported for Latin America and the Caribbean during the period between 2003 and 2008. ${ }^{14}$

The prevalence of wasting and stunting, using the data of these national surveys, has been reported by 
González de Cossío et al, using the WHO 2006 growth standard as a reference. However, they used the weight for age as an indicator, rather than the BMI. ${ }^{15}$

Overweight including obesity. As the children age, obesity increases. Therefore, efforts are required to reduce its incidence and prevalence in childhood. Promotion of healthy living styles, with an emphasis on better feeding practices, should help. The figures concerning breastfeeding reported in the SMNG 09 survey $^{8}$ indicate that this invaluable resource for a child's health is in decline. Therefore, the mother/infant dyad should be promoted, encouraging mothers to start breastfeeding exclusively for the first six months, and with appropriate support of complementary foods the human milk must continue through the first year, and perhaps the second. ${ }^{21,22}$ However, in the interests of preventing children becoming overweight, it is necessary to promote the consumption of healthy complementary foods, reducing foods and beverages identified as risks, as discussed in this issue concerning feeding practices of the SMNG 09.

Stunting concurrent with overweight and obesity. The high incidence of stunting, particularly in rural areas, and the growing prevalence of overweight and obesity in a segment of the population is evident. When children have had normal linear growth and develop obesity in response to a surplus of energy, the first mechanism of adaptation is growth. Therefore, at equal ages obese children are invariably taller; ${ }^{23}$ however, when stunting has already occurred, an increased energy intake does not remedy the stunting. On the contrary, increased food intake produces overweight and obese children. To prevent this problem changes are required in medical and non-medical aspects. The problem is not only the result of nutritional problems, but as Fernald and Neufeld have described ${ }^{24}$ involves socioeconomic variables. When mothers of stunted children are compared with mothers of non-stunted children, the former are younger, of lesser stature and lower educational level, and live in overcrowded conditions. The containment and resolution of the nutritional problems discussed herein require preventive measures, without overlooking the relevance of social, economic and biological factors.

It is interesting to consider that alterations in growth originate in a common trunk, which is the availability of nutrients to a growing body, and deficit or surplus nutrients and energy are reflected in weight and height. Consequently, the solution entails promoting healthy feeding habits from an early age and closely monitoring physical growth, and implementing periodic and ongoing systems to evaluate growth and nutritional status in children.

In conclusion, data from National Surveys demonstrate that rates of LBW and wasting have decreased, but stunting and being overweight remain public health problems. These nutritionals problems, which impact on the future health of individuals, indicate that policies to promote a healthy life style are required, together with prevention, diagnosis and early treatment of non communicable diseases.

Declaration of conflicts of interest: The authors declare that they have no conflict of interests.

\section{References}

I. Claris O, Beltrand J, Levy-Marchal C. Consequences of intrauterine growth and early neonatal catch-up growth. Semin Perinatol 2010;34:207-210.

2. Clayton PE, Cianfarani S, Czernichow P, Johannsson G, Rapaport R, Rogol A. Consensus Statement: Management of the child born small for gestational age through to adulthood: A consensus statement of the International Societies of Pediatric Endocrinology and the Growth Hormone Research Society. J Clin Endocrinol Metab 2007;92:804-8I0. 3. Darnton-Hill I, Nishida C, James W. A life course approach to diet, nutrition and the prevention of chronic diseases. Public Health Nutrition 2004;7:101-121.

4. Secretaría de Salud. Encuesta Nacional de Nutrición 1988. México: Secretaría de Salud, 1988.

5. Rivera-Dommarco J, Shamah-Levy T, Villalpando-Hernández S, González de Cossio T, Hernández-Prado B, Sepúlveda J. Encuesta nacional de nutrición 1999. Estado nutricio de niños y mujeres en México. Cuernavaca, Morelos, México: Instituto Nacional de Salud Pública, 2001.

6. Olaiz-Fernández G, Rivera-Dommarco J, Shamah-Levy T, Rojas R, Villalpando-Hernández S, Hernández-Avila M, et al. Encuesta Nacional de Salud y Nutrición 2006. Cuernavaca, México: Instituto Nacional de Salud Pública, 2006.

7. Flores-Huerta S, Martínez-Salgado H. Prácticas de alimentación, estado de nutrición y cuidados a la salud en niños menores de 2 años en México atendidos por el Instituto Mexicano del Seguro Social. México, DF: IMSS, 2004.

8. Muñoz-Hernández O, Cortés-Gallo G, Pérez-Cuevas R, GarduñoEspinosa J, Durán-Arenas L, Flores-Huerta S, et al. Evaluación del Seguro Médico para una Nueva generación. México: Hospital Infantil de México Federico Gómez, 2009.

9. Habicht JP. Estandarización de métodos epidemiológicos cuantitativos sobre el terreno. Bull Pan Am Health Organ 1974;76:375-384.

10. World Health Organization, Expert Committee. Physical status: The use and interpretation of anthropometry In: Report of a WHO Expert Committee, ed. WHO technical report series 854. Geneva: WHO, 1995. II. World Health Organization. Child Growth Standards. [Accessed: 2010 December 13] Available at: www.who.int/childgrowth/en., 2006. 12. World Health Organization. WHO Child Growth Standards. Length/ height-for-age, weight-for-age, weight-for-length, weight-for height and body mass index-for age. Methods and development. Geneva: WHO, Department of nutrition for health and development, 2006.

13. United Nations Children's Fund, World Health Organization. Low birthweight: Country, regional and global estimates. New York: UNICEF, 2004. 14. United Nations Children's Fund. The state of the world's children Special edition. New York: UNICEF, 2009.

15. González-de Cossío T, Rivera JA, González-Castell D, Unar-Munguía M, Monterrubio EA. Child malnutrition in Mexico in the last two decades: prevalence using the new WHO 2006 growth standards. Salud Publica Mex 2009;5I:S494-S506. 
16. Hernández-Prado B, Hernández-Ávila M. Evaluación externa de impacto del Programa Oportunidades 2004. Tomo III Alimentación. Cuernavaca, Morelos, México: Instituto Nacional de Salud Publica, 2005.

17. Rivera JA, Sotre-Alvarez D, Habitcht J-P, Shama T, Villalpando S. Impact of the Mexican program for education, health and nutrition (Progresa) on rates of growth and anemia in infants and young children. A randomized effectiveness study. JAMA 2004;291:2563-2570.

18. Rosado JL, López P, García OP, Alatorre J, Alvarado C. Effectiveness of the nutritional supplement used in the Mexican Oportunidades programme on growth, anaemia, morbidity and cognitive development in children aged I2-24 months. Public Health Nutrition 20 I ; 14:93I-937. 19. Sepúlveda J, Bustreo F, Tapia R, Rivera J, Lozano R, Oláiz G, et al. Improvement of child survival in Mexico: the diagonal approach. Lancet 2006;368:2017-2022.
20. ACC/SCN. Fourth Report on the World Nutrition Situation. Geneva: ACC/SCN/IFPRI, 2000.

21. World Alliance for Breastfeeding Action. Protecting, promoting and supporting continued breastfeeding from 6-24 + Months: Issues, politics, policies and action. Global Breastfeeding Partners Meeting VII. Penang, Malaysia: WABA, 2009.

22. World Health Organization, United Nations Children's Fund. Global strategy for infant and young child feeding. Geneva: WHO/UNICEF, 2003. 23. Sargent JD, Blanchflower DG. Obesity and stature in adolescence and earnings in young adulthood. Analysis of a British Birth Cohort. Arch Pediatr Adolesc Med 1994; 148:68I-687.

24. Fernald L, Neufeld L. Overweight with concurrent stunting in very young children from rural Mexico: prevalence and associated factors. Eur J Clin Nutr 2007;61:623-632. 